\title{
ROSANNA GORRIS CAMOS, Le cygne malade et l'hellébore: Jacques Grévin, poète, traducteur et homme de science engagé
}

\section{Filippo Fassina}

\section{(2) OpenEdition}

\section{Journals}

\section{Edizione digitale}

URL: https://journals.openedition.org/studifrancesi/31508

DOI: 10.4000/studifrancesi.31508

ISSN: 2421-5856

\section{Editore}

Rosenberg \& Sellier

\section{Edizione cartacea}

Data di pubblicazione: 1 août 2020

Paginazione: 388-389

ISSN: 0039-2944

\section{Notizia bibliografica digitale}

Filippo Fassina, «Rosanna gorris camos, Le cygne malade et l'hellébore: Jacques Grévin, poète, traducteur et homme de science engagé», Studi Francesi [Online], 191 (LXIV | II) | 2020, online dal 01 septembre 2020, consultato il 18 septembre 2021. URL: http://journals.openedition.org/studifrancesi/31508 ; DOI: https://doi.org/10.4000/studifrancesi.31508

Questo documento è stato generato automaticamente il 18 septembre 2021.

\section{(c) $(1) \odot$}

Studi Francesi è distribuita con Licenza Creative Commons Attribuzione - Non commerciale - Non opere derivate 4.0 Internazionale. 


\title{
ROSANNA GORRIS CAMOS, Le cygne
} malade et l'hellébore: Jacques Grévin, poète, traducteur et homme de science engagé

\author{
Filippo Fassina
}

\section{NOTIZIA}

ROSANNA GORRIS CAMOS, Le cygne malade et l'hellébore: Jacques Grévin, poète, traducteur et homme de science engagé, in Penser et agir à la Renaissance. Thought and action in the Renaissance, dir. Ph. Desan et V. Ferrer, Genève, Droz, 2020, pp. 195-227.

1 Il presente contributo intende gettare una luce nuova sulla importante e complessa figura di Jacques Grévin, sul quale la critica ha troppo spesso fornito una interpretazione parziale e non corretta, separando la sua attività poetica da quella scientifica. Al contrario, il presente studio intende offrire un ritratto unitario e coerente di questo medico, letterato, poeta e traduttore. In particolare, durante la sua permanenza a Torino, nell'entourage di Margherita di Francia, risulta evidente che il legame fra scienza e letteratura è continuo e caratterizzante in tutta la produzione di Grévin, come dimostrano i paratesti dei suoi trattati scientifici, che sono delle vere e proprie arts poétiques di elevato valore letterario. Analizzando le opere di Grévin, l'A. dimostra in maniera convincente ed efficace come il suo engagement poetico, religioso e linguistico sia profondamente legato al suo progetto scientifico. Per quanto concerne la sua produzione religiosa, vengono presi in esame i sonetti della Gélodacrye e la traduzione delle Prediche di Bernardino Ochino: in essi emergono il senso profondo della carità cristiana, della comprensione e della solidarietà, la lotta contro l'ignoranza e la ricerca della verità, che dà dignità all'individuo. Anche dal punto di vista politico l'impegno di Grévin è notevole, soprattutto nei sonetti delle Ruynes de Rome: in essi, 
l'immagine della città in rovina assume una portata universale e diventa simbolo della decadenza della Francia. La meditazione su Roma e, più in generale, sul destino dell'uomo, è presente anche nella sua tragedia César, in cui, sul modello della tragedia classica e riprendendo anche tematiche care a Du Bellay, viene opposta una città dominatrice, che sacrifica anche gli ideali di libertà per la propria supremazia, a una città che rivendica questi ideali e cerca di ristabilirli. Cesare incarna così il potere magnanimo e clemente, ma, allo stesso tempo, i cospiratori diventano modello di uno spirito sincero, positivo e razionale. Per quanto concerne la produzione scientifica di Grévin, l'A. sottolinea la grande importanza che hanno soprattutto i suoi Portraits anatomiques de toutes les parties du corps humain, in cui viene finalmente creata una terminologia francese per il linguaggio medico e per le parti del corpo umano, ambito in cui precedentemente regnava il caos e l'anarchie lexicale. Anche in questo caso, la finalità non è solo scientifica, ma è accompagnata dalla volontà di arricchire la lingua nazionale e dare un contributo alla collettività grazie alla trasmissione del sapere. Infine, vengono analizzate le sue opere di traduzione. In primo luogo, quella $D e$ praestigiis dæemonum di Johann Wier, in cui è evidente l'impegno di Grévin per contrastare la superstizione e per promuovere la tolleranza nei confronti dei possédés. In secondo luogo, i Deux livres des Venins, in cui confluisce il lavoro di traduzione delle opere di Nicandro: in questo suo studio sui veleni, vengono presentati i rischi che corre un medico nella sua missione, che si deve costantemente fondare sulla coscienza e sul buon senso. In queste opere scientifiche, Grévin sottolinea il carattere fasullo delle fables-sorcières e propone un metodo di studio moderno, basato sulla vraisemblance, sull'analisi delle testimonianze e sul rifiuto della demonologia e della stregoneria, a favore di un approccio medico relativo a questi fenomeni. Nel complesso, di Jacques Grévin viene ricostruito un ritratto di grande interesse e di grande complessità, in cui vengono messi in evidenza il suo curieux désir di unire scienza e poesia, sapere antico e teorie moderne, e la sua doppia missione di poeta e di medico, che hanno la stessa intrinseca finalità, quella di sondare ogni ambito della natura, e di svelare la verità che Dio ha nascosto in ogni aspetto del mondo e dell'uomo. 